\title{
27. COMPARISON OF THREE METHODS OF MEASURING OR ESTIMATING SONIC VELOCITY IN SEDIMENTS ${ }^{1}$
}

\author{
Dean A. McManus, University of Washington, Seattle, Washington
}

Three different methods of determining sound velocity in sediments were used during Leg 5 . This summary provides some tentative comparisons of the results from the various methods as an indication of the potential to be realized from more rigorously controlled measurements and data analysis.

The first of the three methods is an indirect estimate of sonic velocity, determined by comparing the travel times to reflectors on the seismic profile record with the driller's depth to the lithologic unit presumably causing the reflection. The seismic profiling system was arranged to be used while stopped at the site, by having the hydrophone streamer buoyed by floats and by lowering the 20 cubic-inch air gun over the side of the ship. The $20-80 \mathrm{~Hz}$ band of this sound source was recorded on a Gifft recorder using a 5 -second sweep. The travel times of these on-site profiles were then compared with the driller's depths.

The second method used was an Underwater Systems Laboratory sonic velocimeter. The sediment cores in their plastic liners were placed in a transducer head having a $400 \mathrm{kHz}$ peak frequency. The data were in the form of travel time through the core for comparison with travel time in the standard, the same type liner filled with distilled water. The method is described more fully by Peterson et al. (1970).

The third method was down-hole acoustic logging, using a 2-1/8 inch Dresser-Atlas acoustilog tool in the open hole. A 2-1/4 inch caliper log tool was also lowered to measure the hole diameter. The acoustilog tool was constructed so that a sound source having a 25 to $30 \mathrm{kHz}$ peak frequency was in the upper part, and two receivers, one foot apart vertically, were in the lower part of the tool. The data were recorded in the form of the travel time difference between the receivers, expressed as microseconds per foot. A line drawing of the acoustic and caliper $\log$ at Site 35 is shown in Figure 1. The caving of the sides, in all but the basal part of the hole, and the noisy record of the acoustic $\log$ are readily apparent.

Data from three sites have been selected to illustrate the results. Site 34 is selected to represent the sites with

\footnotetext{
${ }^{1}$ University of Washington, Department of Oceanography Contribution No. 520.
}

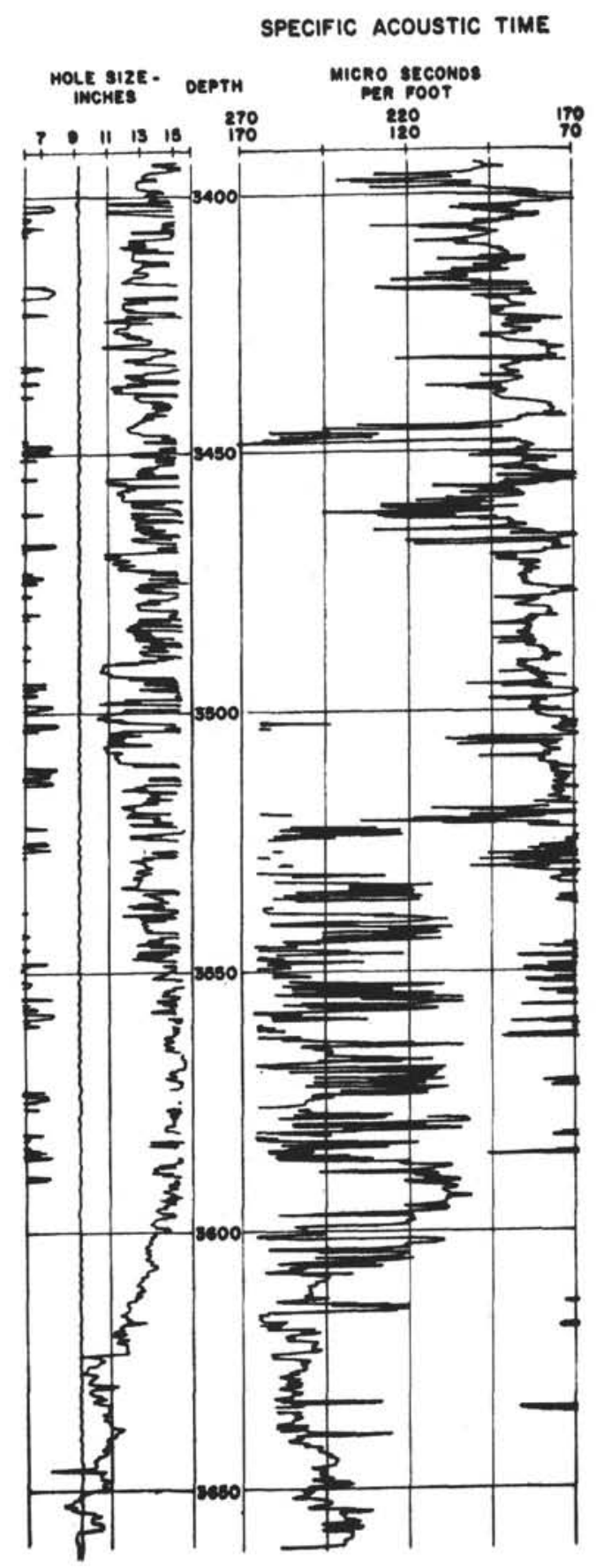

Figure 1. Line drawing of the acoustic and caliper log at Site 35. 
thick sediment sections drilled on this leg. Site 34 shows 0.5 second of sediment overlying the acoustic basement. Consequently, "thick" sediment sections for Leg 5 are tenths of seconds in thickness. Site 37, on the other hand, is selected as representative of the thin sediment sections because the sediment here is only 0.04 second thick. "Thin" sediment sections on Leg 5, therefore, are measurable in hundredths of seconds. Finally, Site 35 is included as the only site on the leg at which a down-hole acoustic log was obtained.

Data from Site 34 are summarized in Table 1. Based upon the seismic profile travel times (T) and the driller's depths to the lithologic units (L), average sonic velocities are computed $\left(\mathrm{V}_{1}\right)$. The table shows the results from the laboratory velocity measurements with the depth in meters of each core below the sea floor together with the number of measurements made on the core. The average velocity for each core is presented; with complete 9-meter core recovery, measurements were commonly made upon each third of the six sections into which the 9-meter core was cut for ease of handling. Thus, 18 measurements were made if the recovery was 100 per cent and if the sediment permitted.

The laboratory-determined velocities for the cores $\left(V_{2}\right)$ are averaged over lithologic units determined from the coring. At Site 34 the upper unit has an average sonic velocity of $1400 \mathrm{~m} / \mathrm{sec}$. An underlying unit of $1444 \mathrm{~m} / \mathrm{sec}$ is recognized as a separate unit, because the sediment contains ash and pyrite not present in the upper unit and because the sediment is firmer. It can be noted that the average velocities of the three thickest units are comparable to averages for these units shown in the column for average sonic velocities. The average for the entire sediment section is $1550 \mathrm{~m} / \mathrm{sec}$ for laboratory determined velocities, and it is $1532 \mathrm{~m} / \mathrm{sec}$ for the seismic-profile driller's depth determination.

Using the laboratory-determined velocities $\left(\mathrm{V}_{2}\right)$, travel times can be computed to the tops of the various lithologic units for comparison with the seismic profile travel times to reflectors $(\mathrm{T})$. The comparison is good even though the data analysis is crude. The closeness of the comparison can be appreciated in spite of the following limitations: (1) The core recovery in the basal part of the hole was poor and, therefore, the recovered sediment is of an uncertain representativeness. (2) The reflector on the seismic profile is assumed to be at the top boundary of a lithologic unit. (3) The laboratory sonic velocity measurements in a highly liquid part of a core section are approximately the same as those made in the firmer sediment in the same core section, indicating uncertainty as to precisely what the laboratory velocimeter is measuring. (4) No in situ temperature corrections have been made.

The data for Site 37 are summarized in the same manner in Table 2. Site 37 represents a thin sediment section, continuously cored to basement. The difference in the average velocity for the entire sediment section as determined by the two methods $\left(\mathrm{V}_{1}\right.$ and $\left.\mathrm{V}_{2}\right)$ is shown to be approximately $100 \mathrm{~m} / \mathrm{sec}$. The comparison of the travel times is close. One realizes, however, that in thin sediment sections (hundredths of a second thick) small errors in laboratory sonic velocity measurements, in reading the seismic profile, or in determining the driller's depth will produce pronounced errors in the average sonic velocity for the sediment section. Yet, if consideration is restricted to hundredths of a second for travel times to reflectors, the comparison is good.

At Site 35 the down-hole acoustic log was obtained; the interpretation is summarized in Table 3. Again, the preliminary nature of these shipboard interpretations should be emphasized. There is no vertical scale for Table 3. The units are generalized lithologic units determined from the coring and down-hole gamma ray and electric logs. The uppermost unit was not logged because the drill string was still in this part of the hole. The data are presented as average specific acoustic times per foot, although considerable noise is present in the record. From these data, average sonic velocities per lithologic unit are computed, and the thickness of the unit is expressed in travel time. The travel time on the acoustic log to the top of a unit can be compared with the travel time on the seismic profile to the reflectors. Because the upper part of the hole is unlogged, the sea floor cannot be used as a datum. Accordingly, the sand at 373 meters depth is assumed to be equivalent to the deepest reflector on the seismic profile at 0.43 second, so that 0.43 second is arbitrarily taken as the datum for comparison. The comparison of the third and second reflectors is relatively good. With the assumption that the unlogged unit has an average velocity of $1386 \mathrm{~m} / \mathrm{sec}$ as in unit 2, the top of the upper unit would be 0.011 second above the sea floor.

On the whole, the comparison of the acoustic log with the seismic profile is very good despite the crude approach. Because of the nature of the sediment, few laboratory sonic velocity measurements were made at Site 35 . In the lower part of the hole the sediment was cored without use of a liner; in the middle part of the hole the laboratory signal was completely attenuated by the sediment; and, in the upper part of the core, the unlogged part, the few measurements that could be made were of somewhat higher velocities than assumed in Table 3 for the unlogged part.

From the sonic velocity determinations made during Leg 5 , it appears that the $400 \mathrm{kHz}$ laboratory velocimeter measurements compare well with velocity estimates made from the 20 to $80 \mathrm{~Hz}$ seismic profile and the driller's depth, when the laboratory measurements 
TABLE 1

Sonic Velocity Data from Site 34

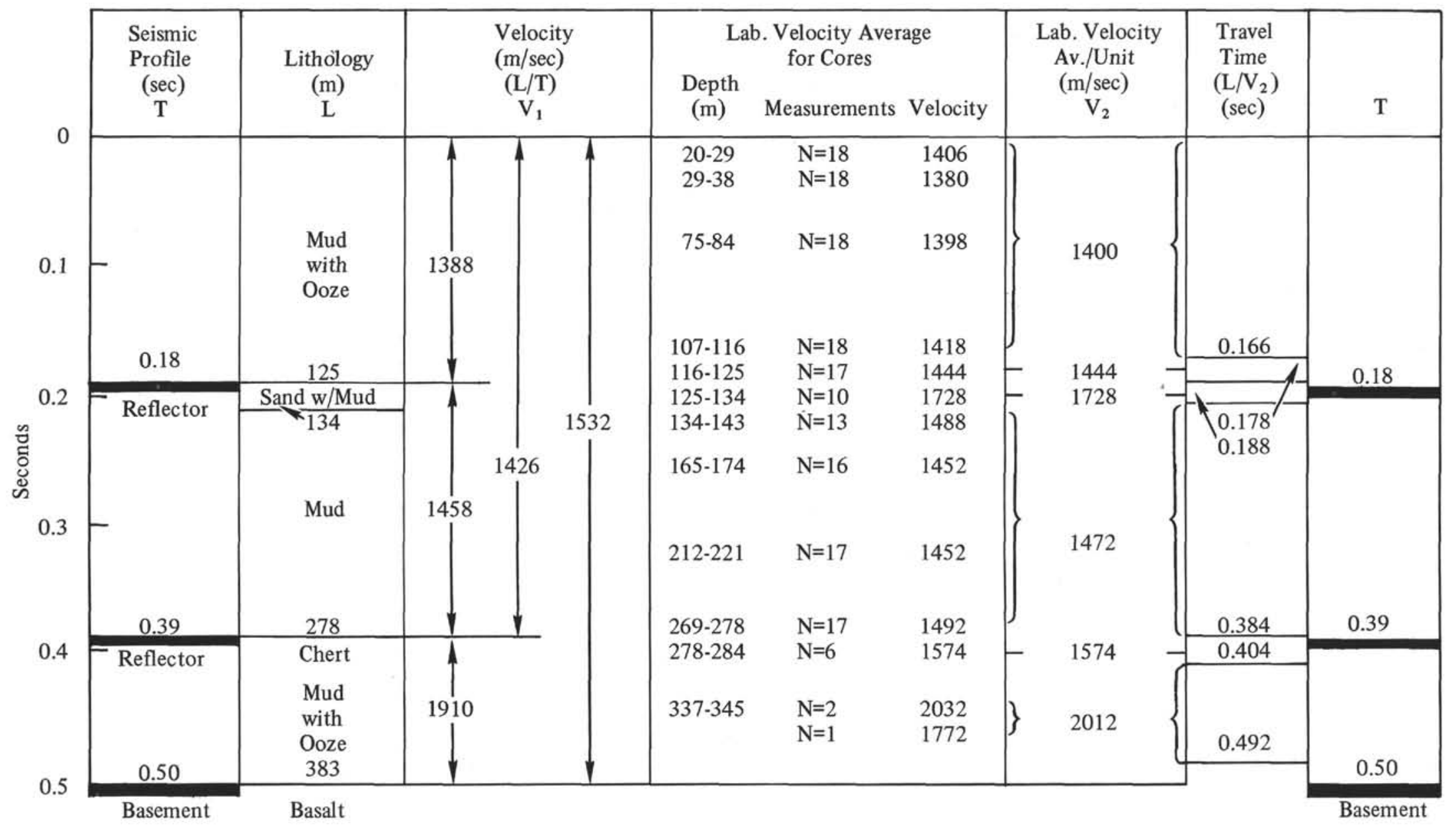


TABLE 2

Sonic Velocity Data From Site 37

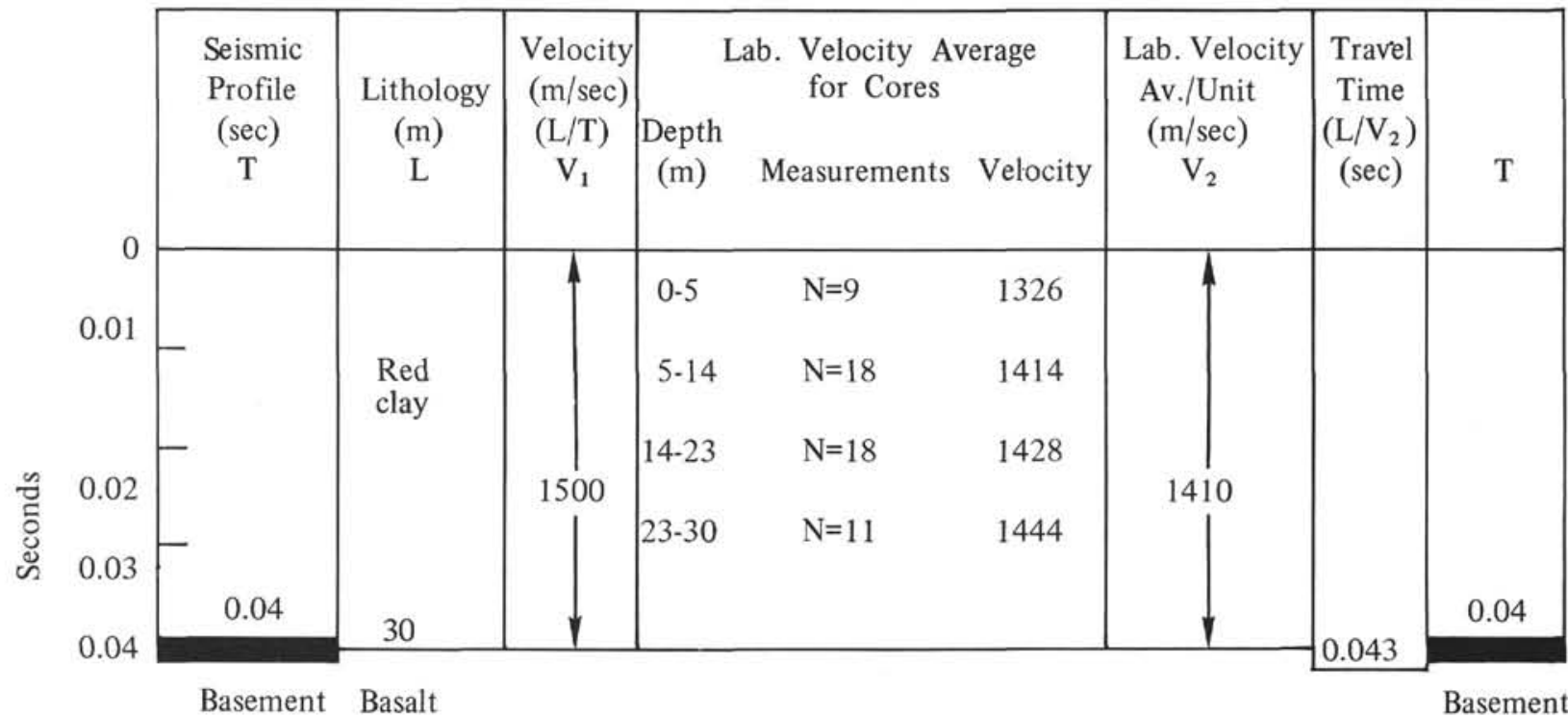

are averaged over a lithologic unit. In sediment sections of tenths of second thickness, it may become possible to compare these methods to a resolution of thousandths of a second. In sections of hundredths of a second thickness or for units of this thickness, comparison is possible only to a resolution of hundredths of a second. The 25 to $30 \mathrm{kHz}$ acoustic log has great potential use, and it appears to be capable of calibrating the seismic profiles in areas where the sediment is of sufficient thickness to permit the use of logging tools. The comparison of laboratory velocity measurements to the acoustic log was not possible. From these measurements, however, it is evident that more rigorously controlled measurements and sophisticated data analysis will soon lead to calibration of seismic profiles.

\section{REFERENCE}

Peterson, M. N. A. et al., 1970. Initial Reports of the Deep Sea Drilling Project, Volume II. Washington (U.S. Government Printing Office), 452. 
TABLE 3

Sonic Velocity Data from Site 35

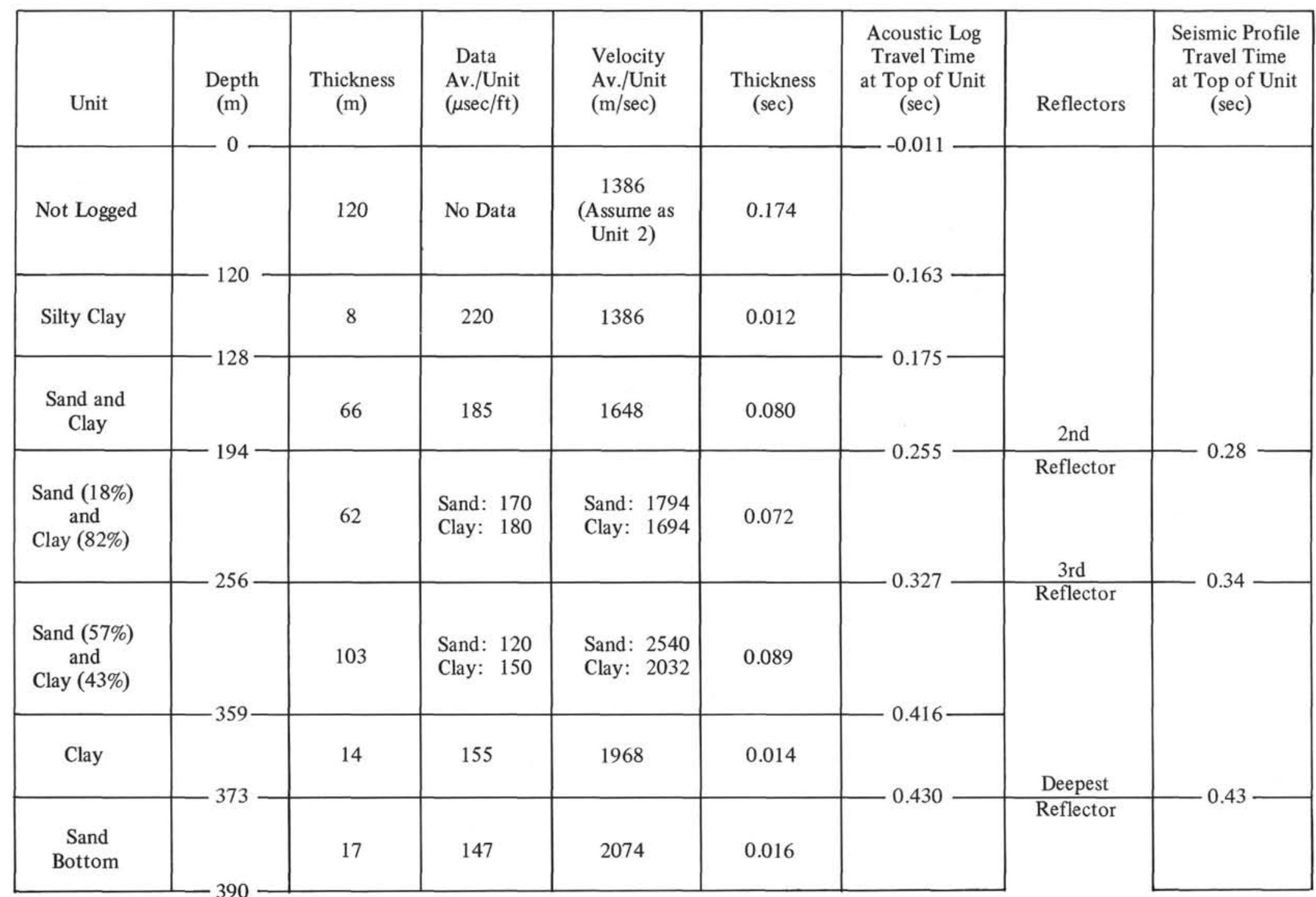

